\title{
Reflexões sobre as bases para a edificação de uma psicologia Kierkegaardiana
}

\section{Reflections on the basis for a building of a Kierkegaardian psychology}

\section{Myriam Moreira Protasio*}

Universidade do Estado do Rio de Janeiro - UERJ, Rio de Janeiro, Rio de Janeiro, Brasil

\begin{abstract}
RESUMO
A obra kierkegaardiana vem sendo objeto de amplos estudos a partir de diferentes áreas de investigação: filosofia, teologia, política e estética. Ocorre-nos perguntar: qual o espaço possível para se pensar uma psicologia em Kierkegaard? Este trabalho quer buscar, a partir da pesquisa acerca do sentido da escolha efetuada por Kierkegaard em dialogar com Sócrates e Cristo, as bases iniciais nas quais podemos pensar o projeto de uma psicologia existencial em Kierkegaard. Para tanto, pretende responder às seguintes questões: o que levou Kierkegaard a construir suas investigações iniciando-as pela figura de Sócrates e do "Conceito de ironia" para, em seguida, assumir como contraponto de todo o seu pensamento a figura de Cristo? Qual o sentido da sua investigação, na voz do pseudônimo Johannes Climacus, sobre a diferença entre o mestre Sócrates e o mestre Cristo? Qual o espaço possível para uma psicologia surgida a partir dessa investigação?
\end{abstract}

Palavras-chave: Kierkegaard, Sócrates, ironia, Cristo, paradoxo, psicologia existencial.

\begin{abstract}
The Kierkegaard's work has been the subject of extensive studies from different research areas: philosophy, theology, politics and aesthetics. It occurs to ask ourselves: in what space is possible to think a psychology in Kierkegaard? This work intends to seek, from the research about the meaning of the choice made by Kierkegaard in dialogue with Socrates and Christ, the foundation on which we can start thinking about the design of an existential psychology in Kierkegaard. To do so, intends to answer the following questions: what led Kierkegaard to build their investigations by starting the figure of Socrates and the "Concept of Irony" to then take as a counterpoint of all his thought and the figure of Christ? What is the meaning of its investigation, the voice of the pseudonym Johannes Climacus, about the difference between the master and the master Socrates Christ? What space is possible for a psychology that emerged from this research?

Keywords: Kierkegaard, Socrates, irony, Christ, paradox, existential psychology.
\end{abstract}




\section{Introdução}

A obra kierkegaardiana vem sendo objeto de amplos estudos a partir de diferentes áreas de investigação: filosofia, teologia, política e estética. O que se pode dizer de sua psicologia? Este trabalho pretende buscar, a partir da pesquisa acerca do sentido da escolha efetuada por Kierkegaard em dialogar com Sócrates e Cristo, as bases iniciais nas quais podemos pensar o projeto de uma psicologia existencial em Kierkegaard.

Kierkegaard desenvolve suas investigações na primeira metade do século XIX, período marcado pelos movimentos humanista e romântico. O idealismo hegeliano era, nesse momento, a corrente mais influente do pensamento filosófico. Ocorre-nos perguntar: o que levou Kierkegaard a construir suas investigações iniciando-as pela figura de Sócrates e do "conceito de ironia" para, em seguida, assumir como contraponto de todo o seu pensamento a figura de Cristo e o próprio cristianismo? Qual o sentido da sua investigação, na voz do pseudônimo Johannes Climacus, sobre a diferença entre o mestre Sócrates e o mestre Cristo?

Para respondermos a estas questões, vamos iniciar tentando compreender o modo como Kierkegaard toma a figura de Sócrates, na qual ressaltamos o projeto de apontar para a negatividade da ironia naquilo que caracteriza propriamente a existência de Sócrates, mas também de todos os homens. Outro elemento colocado em questão por Kierkegaard, com respeito ao Mestre Sócrates, é a possibilidade de que este, na relação com seus contemporâneos, venha a provocar mudanças no modo como estes pensam a si mesmos.

Em seguida, traremos Cristo e o cristianismo, buscando compreender de que forma Kierkegaard, por meio do pseudônimo Johannes Climacus, entende a posição assumida pelo Mestre Sócrates e sua ironia como oposta ao posicionamento tomado pelo Mestre Cristo, ao apontar para a diferença entre conhecer a si mesmo e transformar a si mesmo. Mas também queremos acompanhar o pensamento do filósofo dinamarquês em suas considerações acerca da diferença entre Cristo e o cristianismo, ao entender o primeiro como modelo existencial possível de ser repetido por qualquer homem e o segundo como matriz ética à qual devem estar submetidos todos os homens cristãos.

Traçando essa trajetória estamos indo ao encontro da proposta de psicologia que enxergamos na obra de Kierkegaard. Tal proposta está se afastando da tradição metafísica ou cientifica e propondo uma psicologia pela perspectiva da retomada de outra tradição, cujo fundamento não é mais a apreensão da alma (psique) em suas faculdades ou mesmo como objeto de conhecimento e de experimentação cientifica e totalizadora, mas uma decisão singular, 
um salto, um vir-a-ser, o si mesmo se constituindo nesse espaço em que se articulam o particular e o universal, o indivíduo e a multidão, o temporal e a eternidade.

\section{Sócrates e o conceito de ironia}

Sócrates e sua ironia são o tema da tese de mestrado de Kierkegaard, onde ele afirma que a ironia "fez sua entrada no mundo com Sócrates" (KIERKEGAARD, 1991, p. 23). Desde esse momento, pode-se perceber o co-pertencimento intrínseco ao conceito ironia, que só aparece e pode ser compreendido em meio à situação de seu surgimento, com Sócrates. Kierkegaard está dialogando com a tradição que toma o conceito como um elemento abstrato, lógico, dedutivo ou indutivo ou mesmo eterno, no sentido de seu absoluto acontecimento para além da situação mesma e aponta para a necessidade de que se esclareça a situação originária da qual Sócrates e a ironia podem surgir em sua facticidade. Sócrates não pode ser conhecido fora da ironia, assim como a ironia só pode aparecer por meio de Sócrates. Conhecer a um e a outro exige, então, seguir os indicativos que nos levam até a situação.

Heidegger (1993) esclarece que a palavra situação remete a uma espacialidade e refere-se à posição ou à condição de ser-aí, que se situa na medida em que existe de fato. Por facticidade ele entende 0 "caráter de ser de nosso existir próprio. Mais exatamente a expressão significa esse existir em cada ocasião" (HEIDEGGER, 1999, p. 25). O filósofo alemão esclarece, em seguida: a facticidade, ou a situação, é este estar aqui pelo que toca a seu ser, não em termos intuitivos, ou por meio de uma aquisição ou possessão via conhecimento, mas o existir que "está aqui para si mesmo no como de seu ser mais próprio". Nestes termos o que a situação revela é o caráter fático do ser que é sempre e a cada vez ele mesmo. Aqui nos interessa a situação em que surge Sócrates, a qual aponta para a reciprocidade entre Sócrates e a ironia.

A situação de surgimento de Sócrates se mostra em sua complexidade, a qual denuncia a dificuldade de se conhecer propriamente Sócrates, ou mesmo a ironia, uma vez que o grego vem ao mundo por meio do relato de seus contemporâneos. Kierkegaard recorre aos "ditos de Sócrates conservados" por "seus contemporâneos mais próximos", Platão, Xenofonte e Aristófanes. E é a partir da investigação sobre as diversas possibilidades de aparecimento da figura de Sócrates, que surgem em meio às descrições do cada um destes relatos, que vão se esclarecendo as possibilidades de efetivação do que vem a ser a ironia.

Deste modo ele vai afirmando, indiretamente, que um conceito não pode ser conhecido fora do espaço em que se articula e ganha vida. 
No caso da ironia socrática, esse espaço é o da reprodução dos diálogos socráticos, uma vez que Sócrates não deixou registros escritos. Mas este percurso indireto traz consigo problemas, pois ao reproduzir os diálogos, Platão, Xenofonte e Aristófanes estão mostrando Sócrates, mas também a si mesmos, uma vez que o Sócrates trazido por cada um tem um estilo diferente, uma entonação que faz perguntar pelo que, naquele diálogo, pertence a Sócrates, e o que pertence ao relator. Sócrates, os relatores e a ironia se mostram faticamente nesse enredamento, de forma que "Sócrates só pode ser concebido através de um cálculo combinatório" (KIERKEGAARD, 1991, p. 25).

Para que se esclareça "cada" Sócrates é imprescindível que se conheça a situação. A situação se desenha em sua complexidade: de um lado, muito é dito, de outro, o silêncio, pois o dito se mostra insuficiente para abarcar a totalidade, guardando sempre consigo o não dito, o mistério. Kierkegaard considera, então, que "O misterioso nada, que propriamente constitui a 'pointe' na vida de Sócrates, Platão procurou preenchê-lo dando-Ihe a idéia e Xenofonte com as prolixidades do útil. Aristófanes, porém, conseguiu captar este nada, não como a liberdade irônica, na qual Sócrates a gozava, mas sim de tal modo que ele constantemente mostra a vacuidade que há ai" (KIERKEGAARD, 1991, p.124). Sócrates e a ironia vão aparecendo nesse enredamento negativo, vazio de conteúdo, porque impossível de ser conhecido de uma vez por todas, mas cheio de possibilidades. Nessa trama a ironia vai se mostrando como esse espaço que dá visibilidade tanto ao dito como ao não dito, ao exterior, mas também ao interior, ao particular e ao universal, espaço no qual algo pode ser compreendido.

Conforme Paula (2001, p. 52), Sócrates foi uma figura revolucionária em seu tempo, pois em meio às imposições determinísticas dos deuses e dos costumes em relação à vida dos homens, materializada pela figura do oráculo, ele propõe um retorno à interioridade por meio da escuta ao demônio interior, compreendido como o elemento que recoloca a liberdade frente às determinações impostas. Esse espaço interior não é um vazio abstrato, mas um esvaziar-se em relação às determinações prévias. Já se anuncia o acento dado por Kierkegaard à existência singular, aqui apresentada tipologicamente pela figura de Sócrates. A existência de Sócrates constitui-se no espaço em que se articulam as determinações sócio-políticas de seu tempo (dimensão ética), as suas determinações particulares (dimensão estética), que se perpetuam (dimensão eterna) por meio do relato de seus contemporâneos, os quais chegam até os nossos dias. Essa articulação acontece na temporalidade histórica da existência material de Sócrates, mas também se universaliza enquanto tipo, modelo, forma. Como tipo, Sócrates pode sempre ser repetido no tempo. 
Kierkegaard chama a atenção para os tipos enquanto exemplos, cujo sentido aparece na força vital que eles expressam, definindo um exemplo como aquilo que "vale por todos, típico" (1991, p. 32). Cristo, tal qual Sócrates, surgirá como figura exemplar, que remete à sua possibilidade enquanto tipo universal que, no entanto, só pode se materializar de forma singular na existência histórica que, no entanto, transcende a si mesma ao perpetuar-se no tempo por meio do cristianismo. Tentemos compreender a presença de Cristo e do cristianismo na filosofia kierkegaardiana, buscando apreender de que modo isto pode nos remeter aos fundamentos para uma psicologia.

\section{Cristo e o cristianismo}

A situação do surgimento de Cristo e do cristianismo abre-se em sua complexidade, a partir da qual Kierkegaard coloca em cena, mais uma vez, o problema da historicidade. Sabemos que, tal qual Sócrates, também Cristo nos chega pela voz de outras pessoas, seus discípulos, contemporâneos ou não a ele, uma vez que Cristo não cessa de habitar entre nós, atualizado pelo cristianismo e pela fé cristã. Considerada pela perspectiva da historiografia, a investigação pela vida de Cristo torna-se objeto da ciência natural, que quer provar seus argumentos, saindo à cata de provas (ou ausência destas) que confirmem a impossibilidade ou a veracidade da existência de Cristo. Há, ainda, a investigação que busca nos textos bíblicos as suas cifras, tentando traduzi-las e decifrá-las, num esforço de provar, mais uma vez, a sua veracidade, ou mesmo de retirar dos textos as orientações para o cristão, as quais se eternizam pelo cristianismo. Neste caso, abre-se uma possibilidade de interpretação do texto bíblico, que toma o Cristo como se ele fosse uma lei e estivesse dizendo o que se deve e o que não se deve fazer, apontando para um tipo específico de relação, na qual nos abstemos de uma relação propriamente dita com o Cristo, em nome de uma relação com a lei ditada pelo Cristo.

Considerando que não somos contemporâneos do Cristo e que, portanto, só temos notícias dele por intermédio dos registros escritos, mais se complica a possibilidade de compreendermos a situação e o sentido da vida e da vinda do Cristo. O projeto kierkegaardiano nos parece, neste momento, articulado com o projeto hermenêutico de Schleiermacher, no qual o que importa é alcançar o sentido a partir do qual as palavras estão sendo ditas. Nesse caso a hermenêutica exige um posicionamento diferente daquele exigido pela gramática ou pela retórica, onde importa compreender os elementos do texto ou os elementos do apelo argumentativo em jogo no texto. A hermenêutica, segundo Schleiermacher (2010), exige que se saia da ordem direta da construção do texto e, por um movimento contrário, 
por um salto, alcancemos o sentido a partir do qual as palavras são ditas. Nessa forma de interpretação está em questão a possibilidade hermenêutica na qual, a partir do texto lido, nós estabelecemos uma relação efetiva com a existência propriamente dita do Cristo, a qual torna possível a transformação da nossa existência. Kierkegaard, no entanto, está colocando em cena mais do que um projeto hermenêutico de interpretação dos textos bíblicos. Seu projeto é existencial e se refere ao caráter da possibilidade de transformação de si mesmo que se abre por meio da contemporaneidade entre 0 leitor e o texto lido, entre a vida do leitor e as possibilidades abertas pelo texto. O que realmente importa é a possibilidade de transformação, ou seja, o caráter de abertura às possibilidades, que caracteriza a existência mesma.

Kierkegaard tratará como decisão cada determinação existencial assumida pelo si-mesmo, a qual se desenha na tensão entre a indeterminação originária e o caráter inevitável de ser, ou seja, de se determinar. Ele dirá, no livro As obras do amor (2005), que o ser do homem só aparece por meio de seus frutos, ou seja, na facticidade do existir que é sempre e a cada vez dele mesmo. A facticidade do existir singular é voz da totalidade dos sentidos de seu tempo, ou seja, é particular e universal a um só tempo. Nesses termos, Kierkegaard não está falando em conceitos, ou no conteúdo dos textos, mas no modo como o conceito aparece na particularidade de cada singularidade que é, ao mesmo tempo, uma singularidade e um tipo, ou seja, o que vale para ela vale para todos. O Cristo é, então, ele mesmo e a humanidade, enquanto possibilidade de se concretizar na existência de cada um, podendo ser repetido no tempo.

\section{Mestre Sócrates e o Mestre Cristo ${ }^{1}$}

Sócrates e Cristo foram mestres para seus contemporâneos, e o pseudônimo kierkegaardiano Johannes Climacus, no texto de 1844, Migalhas filosóficas ou um bocadinho de filosofia, se pergunta sobre como é possível que um mestre possa transformar alguém. Este pseudônimo problematiza a diferença entre ocasião e instante, entre conhecer-se a si mesmo e transformar-se a si mesmo. Ele desenvolve que a ocasião é categoria do temporal, a partir da qual as contingências são compreendidas como oportunidade para que a verdade se faça conhecida. Sócrates seria o protagonista da ocasião para que o discípulo viesse a conhecer a si mesmo, pois conhecer a si mesmo é o limite de operação na ordem do temporal. O instante, por seu turno, é categoria do eterno e, nestes termos, funda a possibilidade de uma transformação, pelo que o mestre dá a condição para que o discípulo transforme a si mesmo. O que Kierkegaard tem em mente é a experiência vivida no interior da fé cristã, em que o 
instante, ao cortar o movimento do suceder do tempo, abre o espaço para a transubstanciação da carne em espírito e do espírito em carne, ou seja, para a transformação existencial que se transcende a si mesma, operando na dimensão eterna.

Climacus opondo, neste livro, o mundo grego (estético), na figura do mestre Sócrates, que representa para o discípulo a oportunidade de conhecer a si mesmo; e o mundo cristão (em sua possibilidade ética e religiosa), que representa a possibilidade do discípulo transformar a si mesmo, apresenta o eterno como categoria apenas possível a partir do cristianismo: o deus sendo o mestre que pode dar a condição ao discípulo para que ele encontre a verdade, o que ocorre no "instante", categoria que une de forma necessária o temporal e o eterno, o particular e o universal.

Afirma Climacus (KIERKEGAARD, 1995, p. 34): "Na medida em que o instante deva ter uma importância decisiva", a partir do instante o discípulo se transforma em outra pessoa, uma nova pessoa, não mais submetido à categoria do contingente, mas à categoria do paradoxo. O fundamento dessa transformação é escândalo para a razão. O que vem à tona, na diferenciação entre os dois mestres, é o fato de que conhecer-se a si mesmo é ação temporal, finita, atividade racional que se dá em um momento, enquanto transformar-se a si mesmo é categoria eterna, espaço do clássico, do instante, que "deve ser 'aquilo que importa", pois, uma vez convertida em absurdo pelo paradoxo, "o que a inteligência considera importante já não é critério algum" (KIERKEGAARD, 1995, p. 79). O que está em questão é a existência enquanto espaço onde é possível que se experimente uma transformação impensada, a princípio.

Com Sócrates, que é o mestre mundano, a possibilidade de transformação está submetida à lógica e se desenha no âmbito do conhecimento pautado na sabedoria na vida, ou seja, da existência enquanto regida pela cultura, pela vida em comum, etc. Seu método é o do esvaziamento da experiência ao confrontá-la com sua possibilidade oposta, de forma a que esta tensão converta-se em ocasião para que algo aconteça na vida do discípulo, algo da ordem do finito e do contingente. Com seus argumentos, Sócrates vai desdobrando as crenças de seu interlocutor, inicialmente infundadas, em crenças justificadas, estabelecendo uma nova ordem causal. Em Sócrates, crença e conhecimento se confundem, e o que ele proporciona é a condição para que, eventualmente os homens, que acreditam que sabem acerca de si mesmos possam, efetivamente, conhecer sobre si mesmos. Nessa nova articulação não acontece, realmente, uma transformação existencial, mas o que se dá é a aquisição de um novo saber, de uma nova crença.

O que acontece com o mestre divino é diferente, porque este acena para uma possibilidade de justificativa existencial não pautada em crenças e nem na finitude. O que esse mestre revela não está 
circunscrito no âmbito da razão, mas no âmbito da possibilidade da transubstanciação, ao se desenhar como possibilidade de transformação radical da crença em fé. O que está em questão para Kierkegaard é a possibilidade de uma justificativa eterna para a existência, entendendo o âmbito da eternidade como o âmbito em que a existência encontra a sua seriedade para além do contingente, do temporal e do efêmero. Neste caso não cabe falar em ocasião ou oportunidade, mas em instante. A partir do instante o que se tem é um novo homem, em sua materialidade particular, porque é este homem, mas também universal, porque ele encontrou a sua medida para além dessa materialidade contingente.

O fundamento dessa transformação, a situação mesma em que ela se dá, não pode ser descrita por meio de um encadeamento causal, ou mesmo formal, no âmbito das crenças justificadas. Transformar a si mesmo exige um salto, uma vez que a condição para tal nunca advém de situações contingentes, mas dependem do mestre divino, que é quem pode dar a condição. Nas palavras de Climacus: "No instante ele recebe a condição, e a recebe daquele mestre mesmo". (KIERKEGAARD, 1995, p. 94). Ou seja, transformar a si-mesmo não pode acontecer a partir dos elementos finitos e contingentes, e nem a partir de um encadeamento causal, mas só pode acontecer no instante, que corta o tempo e une, de forma necessária, os elementos da existência, união que não é uma mera junção, mas que confere um sentido que justifica toda a existência.

O cristianismo da primeira metade do século XIX, assim como a filosofia, aparece para Kierkegaard marcado por uma relação de indiferença com a vida mesma, ao considerar a vida pela perspectiva abstrata do sistema de conhecimento ou pela via, também abstrata, do sistema ético. Considerada pela perspectiva da transformação da existência, o que aparece é que a vida só pode ser vivida de forma singular, ainda que o singular não possa existir fora da universalidade, que é a própria existência. Ao colocar em questão o modo cristão de ser enquanto possibilidade para o singular, o simesmo, Kierkegaard está pensando o homem a partir da perspectiva da materialidade fática de sua existência, ou seja, de seus frutos (2005), compreendidos como sendo a forma efetiva e material em que a existência se dá, o que, para ele, é sempre decisão, uma vez que se dá em liberdade e nunca a partir de uma adequação a categorias ou a partir da junção fortuita ou pragmática entre os elementos que a compõem.

\section{As bases da psicologia kierkegaardiana}

Kierkegaard, no tratamento conferido à figura de Sócrates, em sua tese Conceito de ironia, e sob o pseudônimo Climacus, no tratamento 
conferido ao mestre divino, no texto Migalhas filosóficas, está buscando acentuar o caráter de negatividade, ou seja, de indeterminação da existência. As personagens apresentam modos específicos de lidar com a existência, a qual se constitui como uma abertura indeterminada e precária, que não se deixa apreender de forma direta e exige ser abordada de forma indireta. Conforme vimos, logo no início de nosso texto, o que está em questão, na comunicação indireta, é a relação entre o texto e o leitor. O que importa são as possibilidades de transformação da existência, abertas por essa relação. Para nós a constituição de um espaço em que seja possível tal transformação é a tarefa e o desafio primordiais da psicologia. Desta forma, acompanhar a estratégia kierkegaardiana converte-se em exercício para a concretização de tal tarefa. O que importa, agora, é pensarmos de que forma o diálogo construído por Kierkegaard com essas duas figuras, Sócrates e Cristo, nos remete às bases iniciais de uma Psicologia kierkegaardiana.

Kierkegaard, ao tomar as figuras de Sócrates e de Cristo, está pondo em cena o seu método de comunicação indireta, cujo propósito é abrir um espaço no qual uma pessoa, o "seu leitor", possa ver a si mesma no texto e julgar sua própria existência, averiguando se esta se encontra fundada em crenças justificadas - prazeres, deveres cotidianos, etc, ou se ela encontrou sua seriedade, ou seja, encontrou sua justificativa eterna a partir do esvaziamento de toda justificativa temporal. Em lugar de uma comunicação direta, que tem algo a mostrar ou a exigir, a comunicação indireta constitui-se na estratégia de dizer como quem não diz, retirando-se para que o leitor possa ver a si mesmo no comunicado.

Com relação a Sócrates, o elemento a ser ressaltado não é a habilidade argumentativa ou dialética, mas o elemento negativo da ironia que, retirando-se, deixa o outro entregue a si mesmo. Este vazio, aberto pela negatividade irônica, constitui-se no espaço em que tudo é possível, ou seja, nenhuma determinação prévia ou póstuma é determinante, ao mesmo tempo em que sempre se determinará de algum modo. No entanto, este vazio de determinações não é carente de referências, de onde surge outra necessidade, a de se ter a ironia sob domínio, pois apenas ao ser dominada a ironia surge em sua máxima possibilidade, conforme afirma Kierkegaard (1991, p. 279):

A ironia, como um momento dominado, mostra-se em sua verdade justamente nisso: que ela ensina a realizar a realidade, a colocar a ênfase adequada na realidade. (...) Com isso, a realidade adquire o seu valor, não como purgatório - pois a alma não deverá ser purificada de modo a, digamos, sair desta vida totalmente nua, branca e despojada - mas sim como história, na qual a consciência se entrega sucessivamente - porém de tal modo que a 
felicidade não consiste em esquecer tudo isso, mas em permanecer presente aí.

Recorremos à obra póstuma Ponto de vista explicativo da minha obra como escritor, onde Kierkegaard desenvolve, detidamente, o tema da ironia, ao apresentar o contexto total de seu projeto, ao qual ele se refere como sendo o tornar-se cristão, "ou tornar-se homem' (...), pois homem a gente não é, a gente se torna" (VALLS, 2000, p. 189). O que está em questão para ele, neste trabalho, é evidenciar que havia um propósito total em sua obra, e que este não se resume a este ou aquele trabalho, mas ao conjunto total da obra, que teve sempre em vista a possibilidade da transformação existencial do seu leitor. Ele explica que, para tanto, fazia-se necessário construir um caminho que tornasse possível ao leitor considerar a sua própria existência, julgando a si mesmo e, quem sabe, transformando a si mesmo. A ironia dominada se configura, então, como esse caminho, em que aparece a possibilidade de que o leitor, ao julgar a si mesmo, encontre a "ênfase adequada" a ser imposta à sua existência, na qual a vida pode alcançar a sua sacralidade, ou seja, a sua justificativa eterna.

Considerado nesses termos, o tempo da existência não se configura como um purgatório, ou seja, um espaço de sofrimento ou de um esvaziamento que "limpa" o existente de seus pecados e o encaminha para uma felicidade além do tempo, mas como um espaço em que algo "pode" acontecer, algo que pode encher a existência de um sentido, o qual não recusa a realidade, mas aprende a amá-la, abrindo a possibilidade da experiência histórica, ou seja, da repetição no tempo. A ironia relaciona-se, então, com o tempo da existência, enquanto espaço de aprendizado acerca de si mesmo.

O caráter histórico da existência implica o estar presente para si mesmo na co-pertinencia do passado, do presente e do futuro. Ao referir-se à figura de Cristo, Kierkegaard está usando a linguagem indireta para apontar para a contemporaneidade (o hoje) de um Cristo histórico (o ontem) que está remetido ao eterno (o amanhã). Cristo, como filho de Deus, é aquele que foi que é e que será. Nestes termos, a figura de Cristo aponta para nós mesmos em nossa situação de termos-sido, de sermos e de virmos-a-ser. Essa coetaneidade com o sentido articulado pelo texto, para qual o texto bíblico nos remete, instala uma atmosfera de seriedade, conforme a palavra usada por Vigilius Haufniensis. Isto é um completo escândalo para a razão. A relação com o Cristo e com o Deus (o eterno), presente nos textos bíblicos, pode, então, "ensinar" sobre o caráter de urgência da existência. A temporalidade do eterno nos exige uma justificativa para nossa existência para além do contingente e do finito, ou seja, das razões pragmáticas da vida cotidiana. Tal aprendizagem pode acontecer quando o existente se deixa educar 
pela angústia e pela adversidade (KIERKEGAARD, 2010, p. 171 e 2007, p. 180).

Em um texto de 1851, sob o título Para um exame de si mesmo recomendado a este tempo, Kierkegaard (2011) trata deste tema, qual seja, de uma relação de coetaneidade com o texto bíblico por meio da qual o cristo bíblico aparece como um tipo possível, e o que vale para ele pode valer como referência para que o leitor julgue a si mesmo. Kierkegaard está colocando em cena, de forma negativa, porque não expressa de forma direta, relações possíveis com os textos: uma, na qual está em questão o ler as escrituras ao modo de uma tradução das palavras, o que exige que se tenha uma certa erudição, considerando que "a escritura foi escrita em um idioma estranho" (KIERKEGAARD, 2011, p. 44). Seguindo as reflexões de Schleiermacher, Kierkegaard está considerando algumas possibilidades hermenêuticas de consideração do texto bíblico. A primeira, uma pura tradução das palavras, contrasta com outra, a de se tomar o cristo como um provedor de critério ético, que deve ser seguido à risca por seus discípulos. Mas há, ainda, a possibilidade de uma relação na qual o texto surja como um espelho, onde o que importa é poder ver-se a si mesmo no texto lido. Diz Kierkegaard: "Antes de tudo se requer que não vejas o espelho, que não olhes 0 espelho, mas sim que vejas a si mesmo no espelho" (KIERKEGAARD, 2011, p. 43), de forma a que possamos dizer a nós mesmos, enquanto olhamos o espelho: "é a mim que ele fala, é de mim que ele fala" (KIERKEGAARD, 2011, p. 59).

O texto ganha, então, uma dimensão de contemporaneidade entre a situação descrita e a vida fática do leitor, colocando em cena uma relação em que o texto e o leitor se encontram no mesmo pathos, na mesma atmosfera, ou seja, se contemporizam. Desta forma Kierkegaard está apontando para o caráter singular de toda compreensão que, ao mesmo tempo, não pode prescindir da universalidade característica dos tipos possíveis.

Ao colocar em questão o tema da compreensão do Cristo por meio dos textos bíblicos, Kierkegaard está, ao mesmo tempo, apontando para o si mesmo como aquele que, necessariamente, nos pertence e nos é devolvido, em toda e em qualquer situação. Este que nos é devolvido não é, também, nada mais que um tipo, uma possibilidade, e um problema, uma vez que sua determinação não elimina outras determinações possíveis. Sendo assim, o ser não é, sequer, confiável, no sentido de uma determinação em que possa descansar, mas continua sendo um constante problema, que só pode ser resolvido no curso do próprio existir, da própria relação que nos constitui. Mas transformar a si mesmo implica poder ver para além do objetivo, do contingente, do lógico, característico de uma relação abstrata com o texto e com a vida. Transformar a si mesmo é um acontecimento concreto, uma decisão que se configura como modo de ser. Sugere 
Kierkegaard, falando a partir da relação estabelecida entre o leitor e o texto bíblico (2011, p. 62):

\begin{abstract}
Se a palavra de Deus é para ti somente uma doutrina, algo impessoal, objetivo, então não há nenhum espelho - uma doutrina objetiva não pode chamar-se um espelho; contemplar-se no espelho de uma doutrina objetiva é tão impossível quanto fazê-lo em um muro. (...) Não, durante a leitura da Palavra de Deus, deves dizer-se continuamente: é a mim, é de mim que se fala
\end{abstract}

Mais uma vez aparece o caráter circular, o caráter de um "salto combinatório" próprio do projeto hermenêutico kierkegaardiano. Não se trata de Sócrates, nem de Cristo, nem da palavra de Deus, mas do si mesmo, colocado em questão por Sócrates, no mundo grego, e por Cristo e pela Bíblia, no cristianismo. O que ambos têm em comum é o posicionamento negativo, assumido pela ironia, com Sócrates e pelo paradoxo, com Cristo. Kierkegaard afirma, em sua tese, que a ironia constitui-se em espaço de liberdade. Sendo negativa, a ironia mantém o sujeito "negativamente livre e, como tal, flutuante, suspenso, pois não há nada que o segure" (KIERKEGAARD, 1991, p. 227), do ponto de vista da razão. Sócrates, com sua ironia, diz que nada pode ser ensinado, mas que o discípulo pode aprender, na medida em que conhece a si mesmo. O mestre, neste caso, pode levar o discípulo a um lugar que ele poderia chegar por si mesmo. 0 paradoxo é diferente, porque o mestre Cristo não ensina nada e o discípulo não pode aprender nada por vontade ou por meio do conhecimento de si mesmo. O mestre divino pode, apenas, dar a condição, o que exige do discípulo uma entrega, sem qualquer garantia de que algo será alcançado. Mas, ao mesmo tempo, ele pode receber tudo. O paradoxo aponta, então, para o caráter precário, transcendente e ilógico da existência, que precisa alcançar a sua própria justificativa, sem que, no entanto, o existente possa alcançála a partir de si mesmo, por meio de uma autoconsciência ou do cumprimento de etapas previamente determinadas.

Desta forma podemos pensar que o espaço terapêutico deve se constituir ancorado na fé nos possíveis, de modo a que o processo ali aberto se efetive como condição de possibilidade para a transformação e não se restrinja a uma mera junção de elementos que apontem para o conhecimento de si. Traçaremos, abaixo, algumas considerações no sentido de explicitar melhor essa nossa compreensão. 


\section{Considerações finais}

O objetivo deste artigo foi dar os primeiros passos no sentido de fundamentar uma psicologia que tome por base o pensamento do filósofo dinamarquês. Se estivermos certos em pensar que há em Kierkegaard um projeto de psicologia, este deve aparecer em meio aos diversos tipos psicológicos ou, melhor dizendo, diversas possibilidades de existir, construídos pelo filósofo ao longo de toda a sua obra, por meio da apresentação detalhada de alguns existentes típicos. Mas, fazendo isso, ele não estaria construindo uma psicologia classificatória? Ou seja, não podemos, a partir de seus tipos, categorizarmos a nós mesmos e aos nossos contemporâneos? Podemos começar a pensar esta questão apenas lembrando o texto comentado acima (KIERKEGAARD, 2011), onde apontamos que em cada tipo importa não o tipo, mas nós mesmos. Em qualquer situação jamais o que está em questão é o outro, ou o texto, mas nós mesmos no modo como nos posicionamos. O outro é sempre aquele que nos devolve a nós, porque com relação a ele não podemos nada, mas em relação a nós podemos tudo, com a ajuda do possível (o eterno, o infinito), conforme coloca Vigilius Haufniensis, em $O$ Conceito de angústia. Nestes termos, em meio aos tipos apresentados por Kierkegaard, o que está em questão é, sempre, o si-mesmo, no desafio de transformar a sua existência numa existência justificada.

O pseudônimo Haufniensis (KIERKEGAARD, 2010) dirá que para Deus tudo é possível. O acento aqui não deve recair no Deus, adverte ele, como entidade que nos infantiliza e que toma de nós o nosso destino. O acento aqui deve ser colocado no possível, espaço no qual a existência se concretiza e onde ela pode aprender acerca de si mesma e onde ela pode encontrar a sua justificativa. Sendo indeterminados, soltos pela negatividade que nos constitui, a única tarefa que temos, e da qual não podemos escapulir, é a tarefa de sermos o nosso próprio destino (o ter de ser, conforme dirá Heidegger em Ser e Tempo).

O si mesmo é o tema central da psicologia, tratado por essa ciência, em suas diferentes perspectivas, por denominações como ego, consciência, sujeito ou mesmo como comportamento. Assim nos aproximamos um pouco mais do modo como podemos pensar uma possibilidade de psicologia em Kierkegaard, a qual deve se instalar no espaço aberto pela relação entre do si mesmo consigo mesmo. Vigilius Haufniensis vai denominar este espaço de angústia e mais, dirá que é esse o lugar da psicologia. Outro pseudônimo, AntiClímacus, tratará especificamente do si-mesmo e do desafio de conquistar-se a si mesmo no texto $A$ doença mortal, o si mesmo pensado como uma relação que consigo mesma se relaciona e que, nessa relação, precisa se relacionar consigo mesma. Estes temas, angústia e desespero, são fundamentais para que possamos nos 
aprofundar numa proposta de psicologia que tome o pensamento kierkegaardiano como seu fundamento, e devem ser amplamente desenvolvidos, mas tal tarefa deverá esperar outra oportunidade para ser levada a termo.

No momento importa explicitar o sentido do que estamos denominando de bases iniciais para uma psicologia kierkegaardiana, pensadas neste texto por meio da escolha do dinamarquês por dialogar com as figuras de Sócrates e Cristo. Kierkegaard afirma, ao final de seu Postscriptum (2009), que sua obra pseudonimica teve um fundamento essencial, que era a produção poética, que exigia uma neutralidade "a respeito do bem e do mal, frente a compulsão e a jovialidade, ao desespero e à presunção, ao sofrimento e ao gozo" (KIERKEGAARD, 2009, p. 627, tradução livre). Tal neutralidade se determina pela consistência psicológica dos tipos criados pelo filósofo e que ele reconhece como lhe pertencendo, "ainda que só na medida em os coloquei na boca do personagem poético real e criador" (idem).

Tendo esta argumentação do dinamarquês em vista, consideramos que tanto Sócrates como Cristo, conforme aparecem descritos acima, a partir da autoria do próprio Kierkegaard, em Conceito de Ironia, e sob o pseudônimo Johannes Climacus, em Migalhas filosóficas, constituem tipos da variedade psicológica apresentada por Kierkegaard no conjunto de sua obra. O projeto kierkegaardiano, conforme explicitado em sua obra Ponto de Vista explicativo da minha obra como escritor, pode ser resumido como a tentativa de tirar o homem da ilusão de ser quem ele, efetivamente, não é. Nesta tarefa, os tipos psicológicos se constituem em espelhos, nos quais o leitor pode ver a si mesmo e julgar a si mesmo. Neste caso concluímos que as figuras de Sócrates e Cristo nos remetem para duas possibilidades: modificar nossa existência a partir da mera mudança na articulação das circunstâncias, no caso de Sócrates, ou transformar-nos a nós mesmos, por meio da condição aberta pelo mestre divino, que pode nos condicionar para o salto experimentado no instante transformador.

Kierkegaard desenvolverá, ao longo de sua obra, inúmeros outros tipos psicológicos. É nossa interpretação que a psicologia kierkegaardiana encontra nestes tipos sua base, uma vez que cada tipo fala de si mesmo enquanto singularidade, mas também aponta para a universalidade de seu tipo, ao ser possibilidade para todos os homens. Uma psicologia kierkegaardiana deve deixar-se educar pelas tipologias do dinamarquês, entendendo-as em sua condição de tensão entre singularidade e universalidade, finitude e infinitude, possibilidade e necessidade. Tal tensão, no entanto, aparece sempre na figura de cada indivíduo singular, de cada tipo descrito.

Uma psicologia que busque seus fundamentos no pensamento kierkegaardiano precisará transitar pelos problemas trazidos à baila 
por seus diferentes pseudônimos e, tal qual tentamos mostrar acima, deve cuidar para que o espaço da relação terapêutica não se restrinja ao autoconhecimento, mas que se constitua em espaço negativo no qual uma transformação seja possível.

\section{Referências}

HEIDEGGER, M. Ser e tempo II. Petrópolis: Ed. Vozes, 1993.

HEIDEGGER, M. Hermeneutica de la facticidad. Madrid: Alianza Editorial, 1999.

KIERKEGAARD, S. A. Ponto de vista explicativo da minha obra como escritor. Lisboa: edições 70, 1986.

KIERKEGAARD, S. A. O conceito de ironia: constantemente referido a Sócrates. Petrópolis: Editora Vozes, 1991.

KIERKEGAARD, S. A. Migalhas filosóficas ou um bocadinho de filosofia de João Clímacus. Petrópolis: Vozes, 1995.

KIERKEGAARD, S. A. As obras do amor: algumas considerações cristãs em forma de discursos. Bragança Paulista: Editora Universitária São Francisco e Petrópolis: Editora Vozes, 2005.

KIERKEGAARD, S. A. Três discursos edificantes de 1843. Teresópolis: Henri Nicolay Levinspuhl, 2007.

KIERKEGAARD, S. A. La enfermedad mortal. Madrid: Editorial Trotta, 2008.

KIERKEGAARD, S. A. Postscriptum no científico y definitivo a Migajas filosóficas. México: Universidad Iberoamericana, 2009. KIERKEGAARD, S. A. O Conceito de angústia. Petrópolis: Vozes, 2010.

KIERKEGAARD, S. A. Para un examen de sí mismo recomendado a este tiempo. Madrid: Editorial Trotta, 2011.

PAULA, M. G. de. Socratismo e cristianismo em Kierkegaard: 0 escândalo e a loucura. São Paulo: Annablume: Fapesp, 2001.

SCHLEIERMACHER, F. D. E. Hermenêutica: arte e técnica da interpretação. Petrópolis: Vozes e São Paulo: Editora Universitária São Francisco, 2010.

VALLS, A. L. M. Entre Sócrates e Cristo: ensaios sobre a ironia e o amor em Kierkegaard. Porto Alegre: EDIPICURS, 2000.

Endereço para correspondência

Myriam Moreira Protasio

Endereço Rua Barão de Pirassinunga, 62 - Tijuca -

CEP 20521-170 - Rio de Janeiro - RJ, Brasil

Endereço eletrônico: myprotasio@yahoo.com.br

Recebido em: 06/12/2011

Reformulado em: 30/09/2012 
Aceito para publicação em: 11/10/2012

Acompanhamento do processo editorial: Ana Maria Lopez Calvo de Feijoo

\section{Notas}

*Doutoranda em Filosofia no Programa de Pós Graduação em Filosofia da UERJ, Mestre em Filosofia pelo Programa de Pós Graduação em Filosofia da UERJ.

${ }^{1}$ Embora Climacus não se refira, em seu Migalhas filosóficas, ao mestre como sendo o Cristo, ele afirma que se passaram "mil oitocentos e quarenta e três anos entre o discípulo contemporâneo e essa nossa conversa", do que denotamos que o mestre em questão é o Cristo. (KIERKEGAARD, 1995, p. 128). 